Scholz, J. and Duffy, K. (2018) We ARe at home: how augmented reality reshapes mobile marketing and consumer-brand relationships. Journal of Retailing and Consumer Services, 44, pp. 11-23. (doi:10.1016/j.jretconser.2018.05.004)

There may be differences between this version and the published version. You are advised to consult the publisher's version if you wish to cite from it.

http://eprints.gla.ac.uk/162621/

Deposited on: 22 June 2018

Enlighten - Research publications by members of the University of Glasgow http://eprints.gla.ac.uk 


\title{
We ARe at home: How augmented reality reshapes mobile marketing and consumer-brand relationships
}

\begin{abstract}
Augmented reality (AR) has the potential to reshape the mobile shopping experience and create more meaningful consumer-brand relationships. Yet, the broader experiential and brandrelated impact of AR remains unclear, as much existing research adopts an app-centric perspective centered on consumers' motivations for and reactions to using AR applications. The current article takes a more holistic approach to examine what consumer-brand relationships can be facilitated through augmented reality. Through an ethnographic study of Sephora's mobile AR shopping app, we find that a close and intimate (rather than transactional) relationship can emerge due to how the branded AR app is incorporated into consumers' intimate space and their sense of self. This study thus broadens the focus of AR research from the immediate physical context into which virtual information is embedded, to the wider spatial-symbolic context of where consumers use AR apps, as well as to the inner context of how self-augmentations are integrated into consumers' self-concepts.
\end{abstract}

Keywords: Augmented reality; consumer-brand relationship; mobile marketing; retail; brand; engagement 


\section{Introduction}

Augmented reality (AR), which describes the visual alignment of virtual content with real-world contexts (Carmigniani and Furht, 2011; Javornik, 2016a; Scholz and Smith, 2016), is a topic of immense interest for mobile marketing (e.g., Shankar et al., 2016) and retailing research (e.g., Grewal et al., 2017). This is largely due to the early adoption of AR in the retail sector, which is expected to account for about two thirds of the entire AR/VR market's spending in 2018 (International Data Corporation, 2018). While early implementations used in-store installations (i.e., virtual dressing rooms) to overlay virtual clothes and shoes (e.g., Poncin and Mimoun, 2014), more recent AR initiatives utilize consumers' own mobile devices (e.g., Hilken et al., 2017; Poushneh, 2018; Poushneh and Vasquez-Parraga, 2017b; Yim et al., 2017). Leading brands like IKEA, Wayfair, and Sephora have all introduced mobile AR shopping apps that enable consumers to virtually "try out" products on their own bodies or in their own spaces. As augmented reality becomes a central part in mobile marketing's repertoire and allows brands to enter consumers' domestic space with (virtual) offerings, it is crucial to examine how AR might reshape the mobile shopping experience (Shankar et al., 2016).

Recent overview articles have especially highlighted mobile media's potential to build deeper, more "intimate" (Fritz et al., 2017, p. 113; Shankar et al., 2010, p. 112), and "more meaningful relationships with shoppers than what is currently being done" (Shankar et al., 2016, p. 42). Augmented reality seems to be an ideal technology for forging such deeper relationships, as it fuses and entangles branded content with consumers' own environments and bodies (Scholz and Smith, 2016). However, empirical research has yet to thoroughly examine this potential. 
Most previous research on augmented reality marketing has explored the user experience from an app-centric perspective, by examining consumers' motivations for and reactions to using AR applications (e.g., Beck and Crié, 2018; Hilken et al., 2017; Javornik, 2016b; Poushneh, 2018; Poushneh and Vasquez-Parraga, 2017b; Yim et al., 2017). While this research provides important insights into specific aspects of the consumer journey, it remains quiet with regards to the broader question of what consumer-brand relationships can be facilitated through augmented reality.

Furthermore, existing research predominantly examines consumers' responses to AR apps in artificial lab settings that downplay the contexts in which AR apps are used. A few studies examine AR use in real-life-situations (e.g., Dacko, 2017; Poncin and Mimoun, 2014; Olsson et al., 2013); yet, they are mainly or entirely focused on exploring AR in retailing environments. Thus, even though consumers' own homes are one of the top three places where mobile devices are used (Google, 2016), and even though major companies (e.g., IKEA, New York Times, Sephora) pitch their AR apps for in-home use, little is known about how consumers use mobile AR apps within their domestic space. To better examine consumers' holistic, brandrelated responses that result from using augmented reality applications in their homes, studies "in-the-wild" are needed to "investigate interactions in context" (Javornik, 2016a, p. 259). Our research thus adopts ethnographic research methods to address two interrelated research questions:

(1) What are consumers' activities and experiences with an AR shopping app that they use within their domestic space? 
(2) What consumer-brand relationships arise as the retailer is invited into consumers' familiar environments?

We explore these two questions through a consumer ethnography of millennial beauty consumers who use Sephora's mobile AR shopping app. The app provides several non-AR features, such as mobile shopping, as well as an AR-powered "Visual Artist" tool that overlays virtual makeup onto consumers' faces in real time. We employ a multi-method qualitative approach that includes sixteen in-depth interviews and fifty-eight mini-interviews, ten video diaries, content analysis of 3,701 iOS app reviews, as well as in-store and in-app participant observation.

Our findings show how Sephora's mobile AR app is incorporated into consumers' life rhythms. We demonstrate how the brand is invited into the consumer's private space, how embodied interactions with the app allow consumers to get to know themselves and form an intimate relationship with the brand, and how this relationship is challenged through multiple forgivable and non-forgivable transgressions. These findings allow us to make several contributions to our understanding of how augmented reality can foster intimate consumer-brand relationships and, more generally, can reshape mobile marketing. First, our study broadens AR research beyond the focus on visual alignment of virtual and physical objects in the immediate context. To fully understand consumers' meanings and relationships that emerge from their engagement with mobile AR apps, it is important to also consider the wider context and the inner context of the AR experience. By placing a mobile AR experience within a wider spatial and symbolic context, and around a brand-consumer relational core (i.e., the inner context), we can 
discern when nurturing versus transactional relationships are likely to emerge. Thus, our research also answers calls to examine the relationship-building potential of mobile applications (e.g., Fritz et al., 2017; Shankar and Balasubramanian, 2009; Shankar et al., 2016). By discussing the conditions through which a nurturing consumer/brand relationship can flourish, we provide an important counter-point to the transactional undertones that permeate much of the existing literature on mobile marketing (e.g., Fuentes and Svingstedt, 2017; Grewal et al., 2016; Shankar et al., 2016).

Several managerial implications follow from our findings and contributions. We discuss how managers can better leverage the potential of augmented reality by considering consumers' domestic space as an important wider context for their AR apps, by placing the consumer at the center of the app's offerings, and by recognizing what minor imperfections of AR offerings consumers are likely to forgive. In the next section, we review previous AR marketing research and identify what other contexts, beyond the immediate environment in which AR content is embedded in, should be considered for examining AR's relationship-building potential.

\section{Theory}

\subsection{Augmented reality marketing}

Augmented reality (AR) is defined as a real-time direct or indirect view of a physical environment that has been augmented by adding virtual computer-generated information to it (Camigniani and Furht, 2011). Unlike virtual reality, in which consumers are fully immersed in a 
virtual environment, augmented reality allows users to remain within and see the real world (Azuma, 1997), as AR aligns real and virtual objects with each other (Azuma et al., 2001) through various devices such as see-through and monitor-based AR displays (Milgram et al., 1994). AR applications have appeared in marketing practice since the late 2000s (Javornik, 2016c), resulting in new opportunities for consumer engagement (Scholz and Smith, 2016), advertisement (Yaoyuneyong et al., 2016), as well as retail and mobile marketing (Javornik, 2016a). Retailing in particular has embraced augmented reality (Centric Digital, 2016), as several leading brands in the furniture (e.g., Rese et al., 2014), eyewear (e.g., Hilken et al., 2017; Poushneh and Vasquez-Parraga, 2017a, 2017b; Rese et al., 2017), watch (e.g., Yim et al., 2017), and beauty industries (e.g., Centric Digital, 2017) have created AR apps that consumers can use on their own (often mobile) devices. Many of these applications utilize the magic mirror AR paradigm (Scholz and Smith, 2016) to enable virtual tryout and evaluations of products (e.g., Baier et al., 2015) through overlaying virtual products onto consumers' own bodies and faces (e.g., Poushneh and Vasquez-Parraga, 2017a; Hilken et al., 2017; Yim et al., 2017).

Academic research on augmented reality, while still scarce, has rapidly grown over the last few years. After some earlier survey-based (e.g., Huang and Liu, 2014; Rese et al., 2014) and conceptual work (e.g., Javornik, 2016a; Scholz and Smith, 2016), several quasi-experimental and experimental studies (e.g., Beck and Crié, 2018; Hilken et al., 2017; Hopp and Gangadharbatla, 2016; Javornik, 2016b; Poncin and Mimoun, 2014; Poushneh, 2018; Poushneh and Vasquez-Parraga, 2017a, 2017b; Yaoyuneyong et al., 2016; Yim et al., 2017) have provided important insights into consumers' user experience of augmented reality applications. User 
experience is a holistic concept of "how people use an interactive product: the way it feels in their hands, how well they understand how it works, how they feel about it while they are using it, how well it serves their purposes, and how well it fits into the entire context in which they are using it" (Alben, 1996, p. 5). User experience is thus a subjective coming-together of interrelated aspects related to the product itself, the person who interacts with the product, and where a person interacts with the product. Poushneh and Vasquez-Parraga (2017b, p. 230), for example, draw on Hassenzahl and Tractinsky (2006) to describe this concept as encompassing a "user's inner state, product characteristics, and the context of use".

Previous AR research has examined these various aspects of the user experience. With regards to users' inner states, both utilitarian and hedonic values are recognized to drive consumers' attitudes and reactions to augmented reality (e.g., Hilken et al., 2017; Yim et al., 2017). Rauschnabel and collegues (2015), for example, demonstrate that consumers are likely to adopt AR glasses (e.g., Google Glass) for functional benefits (e.g., increasing the efficiency in their lives) and for social signaling effects (e.g., signaling inclusion, or uniqueness, depending on their personality traits). With regards to AR games, such as Pokémon Go, emotional benefits (e.g., enjoyment, nostalgia) and, to a lesser extent, hedonic and social factors (Rauschnabel et al., 2017) have a larger impact on attitude towards AR. The difference in what motivates adoption can likely be traced to the tasks consumers pursue while engaging with AR technology (Javornik 2016a), but also to the type of AR application. Rese and colleagues (2017), for example, found that the relative importance of hedonic (e.g., enjoyment) versus utilitarian (e.g., information) aspects differ between marker-based and marker-less AR applications. Consumers described the 
latter types of apps, which are popular in mobile retailing in form of virtual tryout apps, mainly in terms of how practical, helpful, or useful they found them to be. Their research hence suggests that, even though both utilitarian and hedonic aspects motivate AR shopping app use, utilitarian considerations are more dominant for consumers. These findings align with other research which, by examining consumers' actual and anticipated use of AR shopping apps in real-life situations, found that utilitarian aspects (e.g., making purchase decisions more efficient and confidently) were the most important benefits consumers sought from AR apps (Dacko, 2017; Olsson et al., 2013).

Previous research has also examined what AR product characteristics positively impact consumers' attitudes and behavioral intentions to AR apps. For self-augmentation apps that are often used in mobile retailing (e.g., Ray-Ban, Sephora), high levels of augmentation quality, informativeness, interactivity, and utility have been found to lead to higher user satisfaction (Poushneh and Vasquez-Parraga, 2017a). Poushneh (2018) empirically differentiates between three different attributes that contribute to augmentation quality: Information quality describes the level to which an AR app provides users with relevant and sufficient amounts of useful and trustworthy information; correspondence quality refers to the degree to which an AR app correctly maps the virtual content onto the corresponding location in the real-world physical context; and user empowerment alludes to the degree to which an AR app improves consumers' capabilities to accomplish certain tasks. In addition to these quality attributes, other research also includes hedonic and aesthetic quality as important product attributes that impact user experience of AR apps (Poushneh and Vasquez-Parraga, 2017b). Furthermore, the degree of how interactive 
AR applications are (Poushneh and Vasquez-Parraga, 2017b) and how vivid or real the virtual content looks (Yim et al., 2017) have been linked to important outcome variables, such as user satisfaction, attitude towards the AR app, and willingness to buy.

Research on augmented reality frequently points out how embedding virtual information within consumers' immediate context can reduce uncertainty about a potential purchase (e.g., Beck and Crié, 2018; Javornik, 2016b; Poushneh, 2018; Poushneh and Vasquez-Parraga, 2017b; Yim et al., 2017). Hilken and colleagues (2017) empirically show that environmentally embedding branded content in physical contexts relieves consumers from the mental burden of imagining a product. Drawing on a situated cognition perspective, which holds that people can off-load cognitive tasks onto the environment and use the situational context to solve problems (Brown et al., 1989), Hilken and colleagues (2017) thus present AR as a technology that is able to convey information in better ways than, for example, webpages that display information removed from consumers' immediate physical contexts.

While previous research has thus provided many insights into the AR user experience, it has focused predominantly on consumers' immediate reactions to AR content, displayed in their immediate context. While important, these insights emphasize very specific aspects of the consumer journey - predominantly acquiring product information - based on isolated episodes of exposure to the AR app. Javornik (2016b, p. 19) points to the importance to go beyond such "fragmented consumer responses and provide a more holistic understanding of the experiential value that AR features create for consumers", as well as the need to better understand brandrelated responses, rather than app-related responses, that can be achieved via AR. 
One brand-related outcome that is of interest in the mobile marketing literature is to build "deeper and more meaningful relationships with shoppers than what is currently being done" (Shankar et al., 2016, p. 42). Self-augmentation apps that employ the magic mirror paradigm (Scholz and Smith, 2016) should be especially apt at creating such "intimate" (Fritz et al., 2017, p. 113; Shankar et al., 2010, p. 112) consumer-brand relationships, since brand related content is displayed on consumers' own faces and bodies. However, while previous research sometimes alludes to AR's potential to "foster positive customer-brand relationships" (Poushneh and Vasquez-Parraga, 2017a, p. 100), AR's impact on brand relationships has evaded systematic examination thus far. To do so, the next two sections examine how factors beyond the AR app and the immediate physical context might shape consumers' AR experiences. We consider how the wider context in which consumers use mobile AR applications, as well as AR's potential impact on consumers' sense of self (i.e., the inner context), may affect consumer-brand relationships.

\subsection{The wider context of augmented reality}

In this study, we define the wider context as the different environments in which media technologies are consumed. According to the triple articulation of media technologies framework (Hartmann, 2006; Courtois et al., 2012), consumers' use of media technologies is informed by the meanings of (1) media technologies as objects, (2) media texts, and (3) the wider physical and social environment. For the context of augmented reality, the media object corresponds to the device through which AR content is accessed (e.g., a mobile phone or a pair of smart glasses; Rauschnabel et al., 2015), and the media text relates to the AR content - including how the 
content is mapped onto the corresponding real-world locations (i.e., correspondence quality; Poushneh, 2018).

Previous research has thus examined the immediate context as part of the media text, rather than exploring how the user experience unfolds in the "entire context" (Alben, 1996, p. 5) or the wider physical environment (Hartmann, 2006; Courtois et al., 2012). The wider context of where AR technology is consumed is typically downplayed: While a few studies have examined how AR is used in physical environments such as shopping centers (e.g., Olsson et al., 2013; Poncin and Mimoun, 2014) and public spaces (e.g., tom Dieck et al., 2018), most studies are conducted in artificial lab settings that remove aspect of the wider context through their experimental design. However, AR is often accessed via mobile technologies that can be used across a variety of public and private spaces (Courtois et al., 2012; Google, 2016), and many companies (e.g., IKEA, New York Times, Sephora) pitch their AR apps to consumers for athome use.

Recognizing the wider context as an important aspect of consumers' experiences with AR applications calls for considering differences between private and public spaces. Consumers' homes serve as places for autonomous activity without notable interruption, and offer safe spaces for self-reflection and creative self-expression (Bradford and Sherry, 2015; Livingstone, 2002; McCracken, 1989). Consumers' homes are thus spaces of both symbolic and practical significance for AR use; yet, their impact on consumers' experiences and AR's relationshipbuilding potential remains unknown. The current research explores what consumer-brand relationships emerge when AR is used in the wider context of in-home use. 


\subsection{The inner context of augmented reality}

AR shopping apps that augment consumers' own bodies and faces are likely to not only provide consumers with information about the product, but also to impact their own sense of self. We draw on Belk's $(2013 ; 2014)$ notion of the extended self in digital environments to conceptualize this more internal aspect, or inner context, of augmented reality. AR's impact on consumers' selves can stem from both the media object and the media text (Courtois et al., 2012). AR is often displayed via personal devices that consumers carry with them throughout the day (Shankar et al., 2016) and that can become extensions of consumers' own self-identities (e.g., Belk, 2014; Walsh et al., 2010). Yet, to fully understand the consumer-brand relationships that can be enabled through augmented reality, it is also important to examine how the unique features of the AR media text (i.e., the augmentations emplaced in physical environments) may give rise to new types of self.

The ways in which consumers perceive congruity between a brand and themselves is a central focus in consumer-brand relationship research (e.g., MacInnis and Folkes, 2017). This research typically posits that as consumer-brand congruity increases, the brand becomes included in consumers' sense of self (e.g., Park et al., 2013; Reimann and Aron 2009). In their overview of the self-brand congruity literature, MacInnis and Folkes (2017) draw on Belk's (1988) seminal work on how consumers regard products and brands as extensions of their selves. Yet, as Belk (2013; 2014) points out, his original notion of the extended self was developed at a time before social media and virtual worlds, and thus requires to be updated for today's digital environments. And while Belk did not foresee the impact of augmented reality on consumers' lives, he provides 
several examples of how the digital world, as well as the linkages between online and offline worlds, seem to alter our sense of self and self-other relationships altogether.

A common thread in Belk's $(2013 ; 2014)$ reformulation of the extended self-concept for the digital age is the dissolving of boundaries between consumers, others, objects, and brands. Belk (2013, p. 488) draws on Suler (2004) to claim that "cyberspace tends to shift or de-stabilize self-boundary" and that the "distinction between inner-me and outer-other is not as clear" as it used to be, before the emergence of digital technologies. Social media, for example, has given rise to a new sense of aggregated self that is created via a joint project between a consumer and his or her connections on social media (e.g., Belk, 2013; Drenton, 2012). Virtual worlds also provide consumers with much more flexibility to try out alternatives selves through creating one or many avatars. Especially in immersive virtual realities such as massive multiplayer online games (MMOGs), it is often observed that the player becomes the avatar, eradicating any separate distinction between the physical self and the re-embodied self (Bartle, 2004; Belk, 2013). It is conceivable that augmented reality has a similar effect, except that instead of extending the self into the virtual avatar, the virtual information is integrated with consumers' actual embodied self through AR's hybridizing technology.

Overall, Belk (2014, p. 1110) observes a general trend among digital technologies, in that "the mediated technological portion of our self (e.g., as mediated by our wristwatch, smart phone, eyeglasses or digital appointment calendar) is becoming increasingly invisible and taken as a 'natural' part of self'. Drawing on Clark's (2003) notion of the cyborg, Belk (2014) points out how today consumers already claim some digital technologies as part of their inner self. For 
example, people say they know the time of the day before checking on their watch or cell phone, and they rely on smart phones as their extended mind (Chalmers, 2011) to remember things and perform basic calculations. Thus, we argue that self-augmentation apps, while not considered in previous research on the extended self in the digital world, are likely to follow this trajectory: Most consumers would claim that the image they see in a traditional mirror reflects their actual self. Likewise, it is possible that consumers who see their augmented face via a magic mirror AR interface would also claim to see their 'augmented self', even though the face they see is a hybrid between their own face and virtual makeup provided by a brand.

Our analysis draws on these theoretical discussions of the wider and inner contexts of AR experiences, to examine what consumer-brand relationships can emerge from AR use. Before presenting our findings, the next section provides more information about our ethnographic study.

\section{Materials and Methods}

We selected retail brand Sephora as the context for our multi-method qualitative study. We chose this brand because of its ubiquitous presence, successful adaptation to the omnichannel retail environment (Holson, 2017), and early entry into the AR space. Sephora's mobile app introduced AR features with the Virtual Artist tool in early 2016. In the first eight weeks, the Virtual Artist tool was visited 1.6 million times, and consumers tried on 45 million makeup products using the AR functionality (Milnes, 2016). The app provides three different ways to utilize AR (see Figure 1): product try-on, preset looks, and virtual tutorials. The product try-ons 
allow users to apply and fine tune makeup products. Along with this, the pre-set looks feature allows app users to browse between complete makeup styles, and users have the option to view a split screen to compare with the stylized face. Finally, the virtual tutorials teach users how to apply various products to successfully execute a desired makeup style.

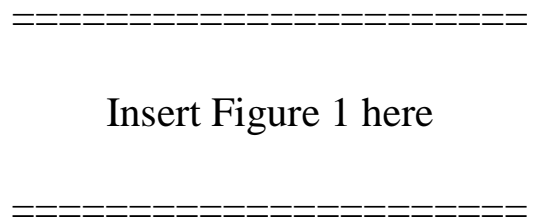

We approached the research in two overlapping phases. During the first phase, we contextualized our field of enquiry through multiple sources (see Table 1). We read relevant articles published in newspapers and industry publications, examined 3,701 app reviews from the iOS app store, and we trialed app functionality ourselves. In addition, we recruited 31 millennial, female consumers (between the ages of 19 and 25) to use the app, and specifically the AR features, over a timeframe of three to four weeks. At the end of this "app exploration" timeframe, each of our participants had regularly explored the app. We conducted up to three rounds of mini-interviews with participants during the "app exploration" timeframe, either face-to-face or in form of video diaries. Overall, phase one included 58 mini-interviews and 10 video diaries.

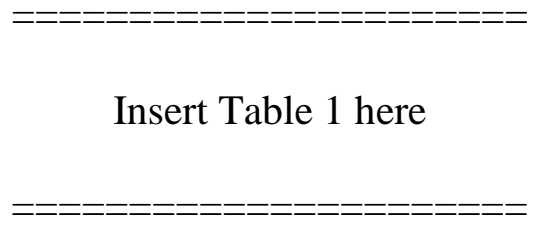


Phase one thus prepared our data collection and analysis during phase two, through familiarizing ourselves with the research context and developing an interview guide. The interview guide was influenced by our initial impressions and discussions of the iOS review data and the mini-interviews / video diaries. Furthermore, the mini-interviews and video diaries provided a screening process for the in-depth interviews conducted in phase two. While we began analyzing the iOS reviews and mini-interview as we collected the data, the actual analysis of the data is part of phase two, and evolved in an iterative fashion as we collected additional data via depth-interviews.

During phase two, our immersion phase, a total of 16 in-depth interviews were conducted and audio recorded (see Table 2). Depth interviews lasted, on average, 1.25 hours and resulted in 418 1.5-spaced, 12-font pages of interview transcripts. Each of these in-depth interviews began with questions about the participant's background before moving into questions about their aspirations, then into their perceptions of the brand, and their use of Sephora's mobile app.

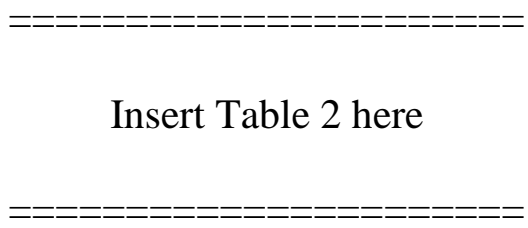

We employed a hermeneutic approach to analyze the data (Arnold and Fischer, 1994; Thompson, 1997). To this end, both researchers analyzed the data first independently, before 
discussing the emerging themes in-person and in over-the-phone meetings. Interpretation and analysis thus involved multiple rounds of refining and interrelating thematic codes across the research team. We develop the final three thematic understandings presented below.

\section{Findings}

We present three thematic understandings from our analysis: Theme one establishes how the brand is invited into the consumer's intimate space, and theme two demonstrates how embodied interactions with the media text (i.e., augmentations of the face) and media object (i.e., device) dissolve the boundaries between the brand and consumers' self, thus foregrounding the consumer and backgrounding the brand. Finally, in theme three we examine how the resulting consumer-brand relationship is challenged through multiple forgivable and non-forgivable transgressions.

\subsection{My Space: Re-configuring the branded app as personal space}

Like previous research on mobile AR shopping apps (e.g., Dacko, 2017; Olsson et al., 2013) and mobile apps more generally (e.g., Fuentes et al., 2017; Shankar et al., 2016), participants in this study use the Sephora app for functionality and convenience: from trialing products and colors on AR, looking at reviews of products, exploring their loyalty points, to facilitating payments and customer services. However, we also note a consumer-brand relationship emerging that extends beyond these points of utility. In this theme, we focus on how consumers invite the Sephora app, and thus the brand, into their private and domestic spaces. 
Through this integration into consumers' intimate life rhythm and 'me-time', the brand achieves a privileged position in consumers' lives that extends beyond a task-oriented relationship of retail. As the branded app infiltrates private time and space, otherwise inaccessible to marketers, we see it emerge as a personal space.

The mobile AR app is invited into the most personal places and even incorporated into consumers' night time routines. By providing an opportunity for consumers to engage with beauty in their own familiar space, the app allows consumers to destress and unwind:

"I just played around with it mostly at night when I was just relaxing or getting ready for bed. And just looking at things that I know I've kind of wanted for a long time... I feel like that was just fun for me to do, and be on my own doing it. I'm not thinking about other people, or where I am, or do I have to get this now? It's kind of just more relaxing." (Violet)

As Violet conveys above, the app facilitates exploration on her time, in familiar spaces, and is an opportunity to focus on herself. This establishes an engagement space which is trusted and cherished. The iOS review below similarly shows how consumers invite the brand into their personal time and space to center on their own needs, away from obligations and commitments of their everyday life:

“...it makes my Sunday. Sunday is the only day I reserve for just ME. I so enjoy shopping on this app." (iOS review)

This movement into the consumer space is further highlighted by Angelica and the pleasure derived from her own beauty practices: "It de-stresses me to just sit down and worry 
about my face." Angelica switches off and focus on a tactile activity, empowering her beauty practices and de-stressing through the interaction and requisite level of concentration. She highlights that she utilizes the app to shut out the world, and focus on herself, whilst simultaneously entering the brand world.

The engagement with the brand that emerges in this private space fundamentally differs from how previous research describes consumers' engagement with mobile apps in more public spaces. While those studies typically present consumers as task focused and conversion oriented (e.g., Andrews et al., 2016; Fuentes and Svingstedt, 2017; Grewal et al., 2016; Holmes et al., 2013; Spaid and Flint, 2014), our participants develop relationships with the brand that are decidedly less transactional and more focused on leisure behaviors (c.f., Grant and O'Donohoe, 2007). As Maddison highlights below, her engagement with the brand combines the intimate space (bed), me-time (lounging), and being "super casual and relaxed", as opposed to feeling pressured to make a purchase decision:

"I could be lounging on my bed and randomly be like, 'I want to look at this product.' Roll over and pick up my phone, and you know, super casual and relaxed. And I feel like there's less pressure. You're probably not making a final decision to buy off this app...This is to get a sense, and then your final decision later will probably be in-store, personally for me." (Maddison)

Participants also found the app as a space of fantasy, which allowed for expressive and playful interaction with themselves and the brand. As Lisa highlights "I'd say it's fun. Yeah definitely more fun and entertainment than usefulness" or as Maddison mentions, "it's just kind 
of a fun thing, playing when I'm bored with the makeup looks." The AR space manifests here as a hedonic space (Hirschmann and Holbrook, 1982; Agrebi and Jallais, 2015; Spaid and Flint, 2014) of inspiration and ideation, which allows consumers to explore their creativity. We see the app allows consumers to interact with the brand in a playful way (Holt, 1995) and to self-express in the safety of their own space. Through this integration of the app into their lives and engaging with the brand in their personal spaces, consumers feel empowered to "be daring in the comfort of my own home" (iOS review) as they are trying out new looks. Kacey, for example, finds that using the app in her own familiar space "take[s] away a lot of the risk". Lydia also describes how the mobile AR app enables her to better express herself than interacting with brand representatives in more official retail spaces:

'I don't like to call myself an introvert, but I'm starting to realize that I'm an introvert, and so I definitely prefer the app better just because... it's not the fact that I don't want to go out and talk to people, but I don't want to take the effort to drive or go somewhere, or make that effort to talk to people.” (Lydia)

Considering the role of the domestic space highlights a unique relationship that unfolds between consumers and the brand. The ways in which the brand is invited into consumer's intimate spaces and 'me time' creates a user experience that is focused on relaxation, play, and entertainment. The next theme further explores the consumer-brand relationship that is formed from the perspective of how the merging between AR content, consumers' embodied selves, and other aspects of AR technology provide an inner context for augmented reality experiences. 


\subsection{My face: Dissolving boundaries and foregrounding the consumer}

Whereas the first theme explores how the wider context impacts the AR user experience, in this theme we examine the ways how AR technology gives rise to new types of self. Core features of the media text (i.e., how AR content is merged with consumers' bodies) as well as other aspects of the media object through which consumer's access AR content (i.e., the touch ID function of the smart phone device) contribute to the dissolving of boundaries between consumers, social others, objects, and the brand. As these mediated objects and texts become 'natural' parts of consumers, they give rise to a consumer-brand relationship in which the consumer is foregrounded, while the brand is backgrounded.

The centrality of the Sephora app in consumers' lives is demonstrated by various comments that declare that "this app is life" (iOS review), a "best friend" (iOS review), and "a savior" (iOS review). The app provides "an interactive mirror", as Lisa explains, that allows consumers to try out different styles and looks in a natural setting. Consumers' own bodies become a canvas for "doing something to their own face" (Lisa), and this embodied experience provides "an actual sense" (Maddison) of possible looks. In more general terms, the app provides embodied, intuitive interactions, using the familiarity of the consumer's own face and mobile device. The consumer herself and her experimentation with different looks thus come to the foreground, whereas the products and brands that are "used" in AR are kept in the background. In short: the experience of play comes first, then the brand comes second. 
Within this framing, the brand becomes implicit as a relationship partner, rather than explicit, and in doing so, allows consumers to play with fantastical looks (e.g., "putting blue lipstick on"; Holly) and become more daring with themselves:

"I could be more of a daredevil with my makeup but I just don't... So, it could've looked super good on me but I wouldn't have known if I didn't use that app...so it helped me so see myself with different kinds of makeup that I would never go out and buy and apply, or even test out in store. [...] I even tried a more punky look, because sometimes I like to think I'm punky, but I'm not." (Chloe)

As the above extract from Chloe demonstrates, the app allows her to get to know herself better, and to take new risks, because she can "see myself". Seeing their own face in new ways allows consumers, for example, to discover their 'inner punk' or bring out their crazy side. Yet, this happens in the safety of their own space (as demonstrated in Theme 1), and more important here, intuitively on their own face as the central point of orientation and embodied interactions. This embodied experience focuses consumers' attention on their own augmented faces, rather than on the prices and packaging of different brands, and thus immerses consumers in interactions with their own selves that are subtly infused with branded content.

The naturalistic interactions enabled by the touchscreen and smart phone sensors further contribute to the blurring between brand, technology and consumer's self. While we focused on consumers' responses towards the media text of the AR app produced by the magic mirror interface, we also noticed how certain aspects of the media object (i.e., device) impact consumers' self-construction and their relationship with the brand. Similar to how seeing their 
augmented selves in the AR mirror, using the touch ID integration when paying for purchases via the mobile app further integrates the brand with the consumer self:

“24-hour store at my manicured fingertips! ...You can save several payment options and now Apple Pay is available. So easy. Touch ID for my iPhone is also a nicely added touch. Love Sephora and that I never have to leave my house for a beauty haul." (iOS review)

"It's nice to be able to use Touch ID instead of typing a password." (iOS review) The tactile act of paying via touch ID is another embodied interaction with the brand. Instead of typing in a password or a credit card number, touch ID allows the app to intuitively 'know' the consumer. Paying for something thus becomes a bodily act, which further dissolves the boundary between consumers and the brand.

The merging of branded content and consumers faces in the magic mirror interface, as well as other technologies that are experienced and utilized in embodied ways (e.g., touch ID), thus shapes the app around the consumer and provides embodied interaction opportunities with the brand. Whilst this allows consumers to know themselves better, we also see the app's AR functionality used for extending sociability around beauty practices:

"I would always sit on the porch with my roommate and mess around with it, and put it on her face. It's so easy because you can have it on your face one second and then out it on someone else's face. Or my guy friends too. It's just entertaining." (Lisa) 
The ease through which a certain look, as defined by the settings chosen within the app, transfers onto a friend's face further highlights the extent to which the mediated technology has become invisible and an almost natural part of oneself. Lisa and her friends are caught up in the social interactions that are facilitated by the branded app, like how consumers might frolic while looking at themselves in a distorting mirror. In each case, consumers would claim that they see 'a version of themselves'. Yet, the branded app does more than just providing a distorted representation of 'what is already there', because it augments consumers' faces with branded content. Even though Lisa and her friend bond over their mutual play with these self-brand hybrids, the role of the brand recedes into the background, while the consumers' selves, their sociability, and play are foregrounded.

In sum, consumers' embodied engagement with AR technology - in form of the media text (e.g., makeup displayed on their face) but also the media object (e.g., using touch ID to unlock the phone and pay for purchases) - dissolves the boundaries between brand and consumers. The brand becomes intertwined with consumers, resulting in meaningful and intimate relationships (Shankar et al., 2010) which we term 'consumer/brand fusions'. Combined with the radical intimacy of the device and its use in intimate consumer space, we thus see the branded app being further configured as a personal space, rather than a task space for engaging in more transaction oriented consumer-brand relationships. In the final theme, we discuss instances in which this intimate consumer/brand fusion is challenged through shortcomings within the AR app. 


\subsection{Protecting and dissolving the consumer/brand fusion}

In this final theme, we explore how the consumer/brand fusion is challenged as certain aspects of app and augmentation quality (Poushneh, 2018) do not meet consumers' expectations. Whether the consumer/brand fusion is shielded from, or breaks down, due to these user experience problems, depends on whether the brand moves from the backdrop to the foreground. As the brand transforms from an implicit entity to a more obvious entity, we see the close relationship between consumer and brand becoming more strained, and in some cases fractured, because the underlying transactional nature of the relationship is being made evident.

Consumers express their dissatisfaction about several glitches and features of the app, ranging from the AR function (e.g., "lipstick colorizer") to individual buttons for adding or removing certain items to/from their list of favorites (e.g., "my loves"). The following quotes present three examples of discrepancies between what consumers expected from the app's functionality, and what they actually experienced (Parasuraman et al., 1988):

"...I wish there was some "save for later" feature on the cart as I often rack up a cart and edit down but it doesn't mean I won't be back soon. I played with the lipstick colorizer, a little brutal to figure out but I eventually figured it and had fun" (iOS review)

"the only reason this wouldn't get 5 stars from me is because of one small feature: removing products from your "my loves" list is So Difficult. I tap the little 'x' in the top corner nearly 30 times, yet I'm only brought to the product page. I want the 'x' button to actually do what it's supposed to. can the software developers 
please fix this?? other than that this app is perfect. [...] I love this app." (iOS review)

"I love this app to death because Sephora is Mecca to me, but there were no bug fixes in the update...the finicky favorites button... it makes using the app super annoying and absolutely needs to be fixed." (iOS review)

The quotes above reveal quality problems related to user empowerment (Poushneh, 2018), as the app is not ideally suited to help consumers accomplish their tasks. Nevertheless, these flaws do not seem to meaningfully affect consumers' close relationship with the brand, as these glitches are downplayed (e.g., "I eventually figured it [out] and had fun") or externalized to parties that lie outside the consumer-brand relationship (e.g., "can the software developers please fix this??"). Thus, even though using the app is "super annoying" for some, the same customers also declare their continued "love" for the app, and claim that "Sephora is Mecca to me".

Given that AR's unique feature is to embed virtual information into the physical environment (e.g., Azuma et al., 2001; Camigniani and Furht, 2011; Hilken et al., 2017), we especially probed our participants on aspects pertaining to correspondence quality, or how well AR content is mapped onto the real world (Poushneh, 2018). Similar to how iOS reviewers externalize responsibilities for less-than-expected app functionality to software developers, we find that interview participants also view shortcomings with the AR functionality as something distinct from their relationship with Sephora as a brand. Allison, for example, notes that "the AR isn't totally on point", but also protects the brand through pre-ambling her criticism by saying that "it's not their [Sephora's] fault really... because it is new technology". We see an 
acceptance that that the app is not perfect, in an understanding and friendly appreciation of expected flaws, but also a continued belief in the brand. In the following two quotes, Maddison and Abby also actively protect the brand:

“... when it scanned your face to then put fake makeup on, it wasn't exactly where my cheekbones and things are. But it's just a little iPhone app, it's not going to be able to do it perfectly. I'm sure an actual [augmented] reality giant set-up would be able to get it more accurate. But for a little app, it was pretty accurate, pretty close on." (Maddison)

"the cat-eye one, it's telling you to put it certain places on your eye. As you move it kind of glitches a little bit. So, it was hard to concentrate when it was moving around. But I know that's normal. If you turn your head or get too close, it kind of alters where you're supposed to put your makeup on... But for that one it was only with the cat eyeliner I think - just because it's so detailed." (Abby)

Both participants are quick to shield Sephora from blame, noting that the AR's shortcomings are "normal" for such a "little iPhone app", which cannot be expected to perform intense beauty work. We thus see, again, how the responsibility for the less-than-hoped-for user experience is externalized away from the brand; this time to the hardware that runs the app, since "an actual $[\ldots]$ giant setup" is expected to provide better results. These quotes highlight that the app is excused for instances in which it was unable to deliver on the expected experience, which are dismissed often as a 'glitch.' We term this as a 'forgivable transgression': The user experience here becomes dissatisfactory; however, the core of the consumer-brand relationship is 
still present. The consumer and their playful experiences are still foregrounded, leading our participants to offer excuses for the app and to externalize the cause of glitches.

Other transgressions, however, are not forgiven, such as when AR content becomes "too virtual" (Diana, below) or when the user experience blatantly reminds consumers that the app is product and brand orientated, as Caitlin highlights below. In these instances, the consumer loses her privileged position as the foregrounded center, which has the potential to damage the cultivated relationship, or prohibit a deeper relationship to arise:

"Every time I would change colors or lashes, when I was scrolling, it would constantly put this little square saying 'Click up here to see products!' or something like that...It was a bit much every time I switched my color. It's already up there, it's not like it's hidden. I would have to wait for it to go away or click on my screen every time. That was probably the most annoying part because I was getting super into checking out the colors, but I was getting annoyed looking at the colors because every time I would this pop-up would come up" (Caitlin)

Caitlin's intimate space and attempt at play is being disrupted by the brand with an overt brand message. We see a difference contrasted here between damaging a formed relationship such as with Caitlin, whereby the relationship is potentially destabilized, and the relationship not emerging at all: 
“... 'Look it’s 3D Diana!' This is so fake. I just will try-on the purple eyeshadow and I'll be like 'oh this doesn't look good.' It doesn't look realistic. Maybe it's just too virtual." (Diana)

As Diana conveys, when the app disappoints with "3D Diana", she is not able to see herself reflected in the magic mirror paradigm (Scholz and Smith, 2016) and to incorporate the augmented content as a "“natural' part of self” (Belk 2014, p. 1110). As a result, Diana is unable to form a deeper relationship with Sephora through the app, in contrast to most of our other participants.

\section{Discussion}

Our research examines how consumers incorporate a branded app into their intimate space and into their sense of self. Both aspects are important for understanding how the AR app can foster a close and intimate consumer-brand relationship, rather than the transactional and utility-oriented relationship that might be more dominant when using AR in shopping centers and other public environments (e.g., Dacko, 2017; Olsson et al., 2013). The intimate, familiar, casual, and relaxing atmosphere of their own homes allows consumers to interact with a brand in ways that feels personal and supportive of self-expression and self-experimentation (Theme 1). This 'outside-in' effect of the wider context is matched by an 'inside-out' effect of the inner context. The integration of branded content with consumers' own facial features, as well as other embodied interactions with the app and the media object (e.g., touch ID), collapses the distance between both relationship partners. In the resulting consumer/brand fusion, consumers' interests 
come to the foreground, while the brand recedes into the background (Theme 2). Both 'outsidein' and 'inside-out' effects open a hedonic, personal space that allows for fluid selfexperimentation and self-expression, enactment of social relationships, as well as play, relaxation, and escape. We indicate this open, fluid, and consumer-centric space through the shaded area that fluidly connects the inner, immediate, and wider context on the left side of Figure 2.

$====================$
Insert Figure 2 around here

While consumers are prepared to defend the consumer/brand fusion, it is not guaranteed to endure because it relies on consumers' perceptions that the brand really cares about them (Theme 3). If the brand's economic and commercial interests come to the fore, or if the AR content is perceived as a wholly artificially layer that does not correspond to one's real face, the consumer does not incorporate the AR content into their self (i.e., the consumer/brand fission in Figure 2). More than just a breakdown of the app, this constitutes a breakdown of the brand/consumer fusion as boundaries between oneself and the brand are made re-evident. This shifts the dynamics of the relationship to a transactional existence, in which the consumer reverts to treating the branded app as a task space to interact with a commercial outsider. Our findings have implications for augmented reality, and mobile marketing more generally. 


\subsection{Considering the wider and inner contexts of augmented reality}

This research adds to the augmented reality marketing literature by broadening our view from the immediate context to the wider and inner contexts of augmented reality. Existing research on AR marketing typically relies on human/computer interaction (HCI) definitions (c.f., Javornik, 2016a) that foreground the visual alignment between virtual and physical objects in an immediate context (e.g., Azuma et al., 2001; Camigniani and Furht, 2011). Focusing on the immediate context is sufficient for app-centric research programs that examine consumers' immediate reactions to an AR app itself: It allows to establish whether and for what reasons displaying sunglasses on consumers' faces, or chairs in their actual rooms, leads to higher purchase intentions than displaying the items on a webpage (e.g., Hilken et al., 2017; Javornik, 2016b; Poushneh and Vasquez-Parraga, 2017b). Focusing on the immediate context also allows for an understanding about how an AR app's efficacy in achieving transactional outcomes can be improved. For example, the HCI lens provides a suitable framework for examining how much the augmentation quality (e.g., Poushneh, 2018) and vividness of AR content (e.g., Yim et al., 2017) impact consumers' satisfaction with an AR app.

However, the $\mathrm{HCI}$ lens has trouble in exploring broader, brand-related questions about augmented reality, as it sidelines the symbolic dimensions of the wider environment as well as AR's impact on consumers' sense of self (i.e., the inner context). Through the current research, we show that these wider and inner contexts matter for understanding what meanings consumers derive from their augmented reality shopping experiences, and what consumer-brand relationships emerge. 
Previous research that examined consumers' use of AR shopping apps in real-life conditions confirmed laboratory studies (e.g., Hilken et al., 2017; Yim et al., 2017) in finding that consumers value AR apps for a combination of utilitarian and hedonic reasons. Yet overall, utilitarian benefits were found to be most important for consumers. Based on a large survey of mobile AR app users, Dacko (2017) found that efficiency in making a shopping decision was the most dominant benefit consumers received from shopping apps, and the one they valued the most. Intrinsic benefits, such as a more entertaining or visually appealing shopping, were also reported by consumers, but valued much less than the extrinsic benefit of shopping efficiency. Using semi-structured interviews, Olsson and colleagues (2013) similarly found that consumers, who were asked to anticipate AR apps, expected both utilitarian and hedonic value, but were mostly concerned with utilitarian aspects such as usability, efficiency, and gaining better information. These previous real-world studies thus emphasize how consumers use mobile AR shopping apps in task focused and conversion oriented ways, making the branded app a task space in consumers' decision-making journey (see Figure 2).

In contrast, our study finds that the final purchase decision is less important in consumers' activities with a branded app, whereas fun and play are valued aspects of the user experience. These differences to previous real-world studies can be reconciled when considered the spatial and symbolic aspects of the wider context in which these studies took place. While previous studies examined consumers' actual and anticipated use of AR shopping apps predominantly (Dacko, 2017) or exclusively within retailing environments (Olsson et al., 2013), our study examines how consumers use Sephora's AR shopping app at home, in their private and 
domestic spaces. Our findings thus suggest that researchers should consider the wider context of AR apps when examining whether hedonic or utilitarian characteristics of the user experience are more important to consumers.

Previous research also explored consumers' experience of AR apps in implicitly transactional terms, by emphasizing how AR apps allow consumers to gain more information about certain products (e.g., Dacko, 2017; Hilken et al., 2017) and increase purchase intentions (e.g., Beck and Crié, 2018; Poushneh and Vasquez-Parraga, 2017b; Yim et al., 2017). By focusing less on AR's impact on consumers' understanding of the product, and more on how AR can shape consumers' understanding of their own selves, our research explores how AR apps can help foster a more-than-transactional relationship between consumers and brands. This perspective provides additional nuance to previous findings on how augmentation quality impacts users' satisfaction with AR applications (Poushneh, 2018). In our study, quality problems with regards to usability and mapping of AR content were forgiven, if consumers still perceived themselves to be the foregrounded center of the consumer-brand relationship.

\subsection{How augmented reality reshapes mobile marketing}

Mobile marketing, defined as "the two-way or multi-way communication and promotion of an offer between a firm and its customers using a mobile medium, device, or technology” (Shankar and Balasubramanian, 2009, p. 118), has quickly become an integral part of the broader digital marketing landscape (e.g., Lamberton and Stephen, 2016). Several overview articles have recently identified augmented reality as an important topic of investigation for mobile marketing, encouraging researchers to examine how AR can drive foot traffic into a physical store (Verhoef 
et al., 2017) or, more broadly, how AR will reshape the mobile shopping experience and the shopping cycle (Shankar et al., 2016). Our research responds to these specific calls to explore augmented reality, but also contributes to the broader project of understanding how mobile media allow marketers to build deeper, more intimate, and more meaningful consumer-brand relationships (e.g., Fritz et al., 2017; Shankar et al., 2016).

According to our findings, AR can indeed result in more intimate consumer-brand relationships, if marketers are able to keep the brand and transactional aspects of the app in the background. Our research thus provides an important counter-point to the mobile marketing literature, which often displays strong transactional undertones by conceptualizing consumers as purchase-oriented shoppers who need to be moved through the various stages of the customer journey. For example, Grewal and colleagues (2016) characterize mobile marketing first and foremost as providing "new opportunities for targeting" communications to "grab [a] particular consumer's attention and move her closer to a purchase" (Grewal et al. 2016, p. 3), Shankar and colleagues (2016) emphasize how mobile media can be used effectively and efficiently to trigger a purchase, and Shankar and Balasubramanian (2009, p. 123) discuss the potential of mobile advertisements and promotions to "overcome the physical (sensory) and psychological (emotional) barriers erected by customers". Consumers are reduced by this view to mere targets for information, who in turn also have been found to adopt a transactional approach to mobile shopping, centered on checking prices and hunting for bargains (e.g., Fuentes and Svingstedt, 2017). 
Our research suggests that these transactional undertones of previous research should not be taken as an inherent feature of mobile shopping, but as a result of the wider contexts that have been examined. Even as it is recognized that mobile media allow marketers to flexibly enter consumers' environments (Shankar et al., 2010), previous work mainly explored mobile marketing in public space and retailing locations (e.g., Andrews et al., 2016; Ghose et al., 2015; Hui et al., 2013; Shankar et al., 2016; Verhoef et al., 2017). Yet, when examining consumers' use of mobile marketing apps in their domestic environments, we observe radically different dynamics. Instead of seeing consumers keeping brands at a distance, and viewing mobile marketing as an intrusion of their privacy or personal space (e.g., Andrews et al., 2016; Grewal et al., 2016; Poushneh, 2018), our participants invite the brand into their lives and sometimes even want the brand to figure them out more, to express themselves more fully. We attribute this difference to the safe, personal space that is created through the 'outside-in' and 'inside-out' processes, in which consumers can create meaningful relationships with the brand. Our research thus draws attention for further explorations of how mobile marketing, with and without AR functionality, can be used for "customer support and other relationship-building activities" (Shankar and Balasubramanian, 2009, p. 118), in consumers' domestic spaces.

\section{Managerial implications}

The findings of this study have several implications for marketing managers and developers of AR shopping apps. Managerial practice and the academic literature on mobile marketing heavily emphasize 'shopping on the go' as the dominant approach to mobile 
marketing (e.g., Fuentes and Svingstedt, 2017; Shankar et al., 2016). Yet, this does not have to be the only application of mobile marketing. Consumers' move to mobile can mean a lot more than just geo-targeting consumers with timely and location-specific information, and savvy marketers will make use of all that mobile devices offer (e.g., Lamberton and Stephen, 2016). This also involves diversifying the marketing mix from (mobile) advertising towards (mobile) content marketing. If marketers and retailers want to truly leverage the potential of mobile to enter consumers' environments, providing valuable content (rather than targeted messages) is essential. According to a study conducted by Google (2016), people use their smart phones more often and for a longer time than their computers, and the place where they use mobile phones the most is their own home. The details provided in our study on how consumers use mobile AR apps at home, and what consumer-brand relationships can arise from these activities, provides mobile marketers with inspiration for what long-term and sustained forms of customer engagement via mobile devices are possible, beyond geo-targeting adverting and internet search on the go.

As marketers create AR apps for sustained customer engagement, they should take care to not fall prey to outdated or overly simplistic views of augmented reality. For example, the practitioner-oriented literature often characterizes AR as little more than an "informationdelivery paradigm" that can help consumers to more "rapidly and accurately absorb information" (Porter and Heppelmann, 2017, p. 53) through embedding information into their immediate contexts. As our study shows, restricting one's perspective on AR to how virtual information is visualized does not fully capture the complexity of meanings consumers associate with a given 
AR app. For this, marketers should consider where the app is likely to be used, and what intentions consumers infer about the brand. In other words, launching a successful AR app requires more than just using the latest and most sophisticated visual engines, but a strategic understanding of how the AR app can help consumers claim the resulting branded environment as their own, with themselves as the center of the app's offerings.

Finally, our research can offer some good news for managers who worry that AR technology is not mature enough to be implemented in their marketing strategies. While we agree of course with Poushneh's (2018) assessment that the quality of the augmentation is important for consumers' enjoyment of an AR app, our findings suggest that an AR app needs to be good and user-friendly, but not perfect, to be successful. Our participants are willing to forgive minor imperfections of the app, if these do not indicate that the brand does not care about the user, or prioritizes its own interests. In other words, brands have a certain leeway when developing their AR apps, especially now, that the technology is not yet mainstream. Thus, our research should encourage managers who are hesitant about the current state of AR technology, and embolden them to embrace AR for their marketing programs.

\section{Future research}

This research has made consumers' activities and experiences with an AR shopping app the focus of attention. It thus answers previous calls for more holistically examining consumers' AR experiences (Dacko, 2017; Javornik, 2016b), how AR reshapes mobile shopping (Shankar et al., 2016), and what deeper relationships between consumers and retailers can emerge through 
mobile apps (Shankar et al., 2010). We introduced the concepts of the wider context and inner context to better understand the meanings consumers associated with mobile AR apps. Future research can capitalize on this broadened view of AR and examine what meanings and relationships arise in non-domestic contexts. Figure 2 shows how the brand can also emerge as a task space (i.e., the dark shaded ring on the right side), which in our study was due to a fission between consumers and the brand, even though the AR app was used in their intimate domestic spaces. Yet, AR apps are also used in public space (e.g., Snapchat's world lenses) and retail spaces (e.g., Lowe's in-store navigation app). Future research that examines how these apps might bring forth other, more task-oriented consumer-brand relationships would further contribute to our understanding of the wider context in which AR experiences are embedded within.

Future research can also go beyond the meanings consumers associated with AR shopping apps, and in addition consider the competencies and materials that are involved when consumers employ mobile AR shopping apps (Fuentes and Svingstedt, 2017; Shove, 2007). In the current research, we focused on the functional, social, and especially experiential meanings consumers derive from AR apps, to examine what consumer-brand relationships emerge from these meaning structures. Future research could employ practice theory to examine, for example, how AR simulations enable consumers to perform certain practices (e.g., wearing makeup) differently. This research would further illuminate the immediate context of AR applications, as it would more thoroughly explore how the visual integration of virtual content with consumers' physical environments can facilitate their consumption projects. 
Finally, future research can also explore in more detail the inner context of augmented reality we introduce through this research. The magic mirror AR paradigm (Scholz and Smith, 2016) is unique in that the consumer sees him- or herself as part of the augmentation. As such, AR content is not only visually integrated with the users' facial and bodily features (Azuma et al., 2001), but also must match consumers' expectations of themselves, in order to be accepted. For example, some of our participants found that the styles presented in Sephora's AR app did not match their skin tone or the level of makeup they are comfortable with, resulting in fissions between their own self-concept and the brand. Future research that explores the short and longterm impact of AR on consumers' selves would be able to further illuminate the inner context of AR experiences. In addition to virtual try-on apps that merely enhance consumers' perceived reality with realistic seeming virtual content, future research could also explore how fantasy oriented AR experiences (e.g., Snapchat's AR lenses) influence consumers' self-concepts and relationships with external entities. 


\section{References}

Agrebi, S., Jallais, J., (2015). Explain the intention to use smartphones for mobile shopping. Journal of Retailing and Consumer Service. 22, 16-23.

Alben, L. (1996). Defining the criteria for effective interaction design. Interactions, 3(3), $11-15$.

Andrews M., Goehring J., Hui S., Pancras J., Thornswood L. (2016). Mobile promotions: A framework and research priorities. Journal of Interactive Marketing 34:15-24.

Arnold, S., \& Fischer, E. (1994). Hermeneutics and Consumer Research. Journal of Consumer Research, 21, 55-70.

Azuma, R. T. (1997). A survey of augmented reality. Presence: Teleoperators \& Virtual Environments, 6(4), 355-385.

Azuma, R., Baillot, Y., Behringer, R., Feiner, S., Julier, S., \& MacIntyre, B. (2001). Recent advances in augmented reality. IEEE Computer Graphics and Applications, 21(6), 34-47.

Baier, D., Rese, A., Schreiber, S., 2015. Analyzing online reviews to measure technology acceptance at the point of scale — the case of IKEA. In: Pantano, E. (Ed.), Successful 
Technological Integration for Competitive Advantage in Retail Settings. Hershey PA, IGI Global, pp. 168-189.

Bartle, R. A. (2004). Designing virtual worlds. New Riders.

Beck, M., \& Crié, D. (2018). I virtually try it... I want it! Virtual Fitting Room: A tool to increase on-line and off-line exploratory behavior, patronage and purchase intentions. Journal of Retailing and Consumer Services. Vol 40. 279-286.

Belk, R.W. (1988). Possessions and the extended self. Journal of Consumer Research, 15(2), 139-168.

Belk, R. W. (2013). Extended self in a digital world. Journal of Consumer Research, 40(3), 477-500.

Belk, R.W. (2014). Digital consumption and the extended self. Journal of Marketing Management, 30(11-12), 1101-1118.

Bradford, T. W., \& Sherry Jr., J. F. (2015). Domesticating public space through ritual: Tailgating as Vestaval. Journal of Consumer Research, 42(1), 130-151. 
Brown, J. S., Collins, A., \& Duguid, P. (1989). Situated Cognition and the Culture of Learning. Educational Researcher, 18(1), 32-42.

Carmigniani, J., \& Furht, B. (2011). Augmented reality: an overview. In Handbook of augmented reality (pp. 3-46). Springer New York.

Centric Digital (2016). How Sephora is Revealing the Future of Augmented Reality in Fashion, September $22^{\text {nd }} 2016$ [online] accessed on April 29 ${ }^{\text {th }} 2018$, available at: https://centricdigital.com/blog/augmented-reality/how-sephora-is-revealing-the-future-ofaugmented-reality-in-fashion/

Centric Digital (2017). How Augmented Reality Could Help Retailers Increase Revenue. March $20^{\text {th }} 2017$ [online] accessed on April 29 ${ }^{\text {th }} 2018$, available at: https://centricdigital.com/blog/augmented-reality/how-augmented-reality-could-help-retailersincrease-revenue/

Chalmers, D. (2011). Foreword, in Clark, A. (Ed.): Supersizing the mind: Embodiment, action, and cognitive extension (pp. ix-xix). Oxford: Oxford University Press.

Clark, A. (2003). Natural born cyborgs: Minds, technologies, and the future of human intelligence. Oxford: Oxford University Press. 
Courtois, C., Mechant, P., Paulussen, S., \& De Marez, L. (2012). The triple articulation of media technologies in teenage media consumption. New Media \& Society, 14(3), 401-420.

Dacko, S. G. (2017). Enabling smart retail settings via mobile augmented reality shopping apps. Technological Forecasting and Social Change, 124, 243-256.

Drenton, J. (2012). Snapshots of the Self: Exploring the Role of Online Mobile Photo Sharing in Identity Development among Adolescent Girls, in: Close, A. (Ed.), Online Consumer Behavior: Theory and Research in Social Media, Advertising, and E-Tail, New York: Routledge, 3-34.

Fritz, W., Sohn, S., \& Seegebarth, B. (2017). Broadening the Perspective on Mobile Marketing: An Introduction. Psychology and Marketing 34 (2), 113-118.

Fuentes, C., Bäckström, K., \& Svingstedt, A. (2017). Smartphones and the reconfiguration of retailscapes: Stores, shopping, and digitalization. Journal of Retailing and Consumer Services, 39, 270-278. 
Fuentes, C., \& Svingstedt, A. (2017). Mobile phones and the practice of shopping: A study of how young adults use smartphones to shop. Journal of Retailing and Consumer Services, 38, 137-146.

Ghose, A., Li, B., \& Liu, S. (2015). Digitizing offline shopping behavior towards mobile marketing. http://aisel.aisnet.org/icis2015/proceedings/eBizeGov/5/

Google (2016). How People Use Their Devices What Marketers Need to Know, September [online] Retrieved February $28^{\text {th }} 2018$, from https://storage.googleapis.com/think/docs/twg-how-people-use-their-devices-2016.pdf

Grant, I., \& O’Donohoe, S. (2007). Why young consumers are not open to mobile marketing communication. International Journal of Advertising, 26(2), 223-246.

Grewal, D., Bart, Y., Spann, M., \& Zubcsek, P. P. (2016). Mobile advertising: a framework and research agenda. Journal of Interactive Marketing, 34, 3-14.

Grewal, D., Roggeveen, A. L., \& Nordfält, J. (2017). The future of retailing. Journal of Retailing, 93(1), 1-6. 
Hartmann, M. (2006). The triple articulation of ICTs. Media as technological objects, symbolic environments and individual texts. Domestication of Media and Technology, 80-102.

Hassenzahl, M., \& Tractinsky, N. (2006). User experience-a research agenda. Behaviour \& information technology, 25(2), 91-97.

Hilken, T., de Ruyter, K., Chylinski, M., Mahr, D., \& Keeling, D. I. (2017). Augmenting the eye of the beholder: exploring the strategic potential of augmented reality to enhance online service experiences. Journal of the Academy of Marketing Science, 45(6), 884-905.

Hirschman, E. C., \& Holbrook, M. B. (1982). Hedonic consumption: emerging concepts, methods and propositions. Journal of Marketing, 92-101.

Holmes, 1., Byrne, A., Rowley, J. (2013). Mobile shopping behaviour: insights into attitudes, shopping process involvement and location. International Journal of Retail Distribution Management. 42(1), 25-39.

Holson, L. M. (2017). How Sephora Is Thriving Amid a Retail Crisis. Retrieved June 20, 2017, from

https://www.nytimes.com/2017/05/11/fashion/sephora-beauty-retail-technology.html 
Holt, D. B. (1995). How consumers consume: A typology of consumption practices. Journal of Consumer Research, 22(1), 1-16.

Hopp, T., \& Gangadharbatla, H. (2016). Novelty effects in augmented reality advertising environments: The influence of exposure time and self-efficacy. Journal of Current Issues \& Research in Advertising, 37(2), 113-130.

Huang, T. \& Liu, F. H. (2014). Formation of Augmented-reality Interactive Technology's Persuasive Effects From the Perspective of Experiential Value. Internet Research, 24(1), 82-109.

Hui, S. K., Inman, J. J., Huang, Y., \& Suher, J. (2013). The effect of in-store travel distance on unplanned spending: Applications to mobile promotion strategies. Journal of Marketing, 77(2), 1-16.

International Data Corporation (2017). 'Worldwide Spending on Augmented and Virtual Reality Forecast to Reach $\$ 17.8$ Billion in 2018. Retrieved February 16th 2018, from https://www.idc.com/getdoc.jsp?containerId=prUS43248817 
Javornik, A. (2016a). Augmented reality: Research agenda for studying the impact of its media characteristics on consumer behaviour. Journal of Retailing and Consumer Services, 30, $252-261$.

Javornik, A. (2016b). 'It's an illusion, but it looks real!' consumer affective, cognitive and behavioural responses to augmented reality applications. Journal of Marketing Management, 32(9-10), 987-1011.

Javornik, A. (2016c). The Mainstreaming of Augmented Reality: A Brief History. Retrieved May $4^{\text {th }}$, 2018, from https://hbr.org/2016/10/the-mainstreaming-of-augmented-realitya-brief-history.

Lamberton, C., \& Stephen, A. T. (2016). A thematic exploration of digital, social media, and mobile marketing: Research evolution from 2000 to 2015 and an agenda for future inquiry. Journal of Marketing, 80(6), 146-172.

Livingstone, S. (2002). Young People and New Media. London: Sage.

MacInnis, D. J., \& Folkes, V. S. (2017). Humanizing brands: When brands seem to be like me, part of me, and in a relationship with me. Journal of Consumer Psychology, 27(3), 355374. 
McCracken, G. (1989). Homeyness: A cultural account of one constellation of consumer goods and meanings. Interpretive Consumer Research, 168-83.

Milgram, P., Takemura, H., Utsumi, A., \& Kishino, F. (1994). Augmented reality: A class of displays on the reality-virtuality continuum. Proc. SPIE Conf. Telemanipulator and Telepresence Technologies, 282-292.

Milnes, H. (2016). Makeup brands are testing augmented reality to drive conversions. Retrieved June 20, 2017, from:

https://digiday.com/marketing/makeup-brands-testing-augmented-reality-driveconversions/

Olsson, T., Lagerstam, E., Kärkkäinen, T., \& Väänänen-Vainio-Mattila, K. (2013). Expected user experience of mobile augmented reality services: a user study in the context of shopping centres. Personal and ubiquitous computing, 17(2), 287-304.

Parasuraman, A., Zeithaml, V. A., \& Berry, L. L. (1988). Servqual: A multiple-item scale for measuring consumer perc. Journal of Retailing, 64(1), 12. 
Park, C. Whan, Eisingerich, A. B., \& Park, J. W. (2013). Attachment-aversion (AA) model of customer-brand relationships. Journal of Consumer Psychology, 23(2), 229-248.

Poncin, I., \& Mimoun, M. S. B. (2014). The impact of "e-atmospherics" on physical stores. Journal of Retailing and Consumer Services, 21(5), 851-859.

Porter, M. E., \& Heppelmann, J. E. (2017). A Manager's Guide to Augmented Reality. Harvard Business Review, 95(6), 45-57.

Poushneh, A., \& Vasquez-Parraga, A. Z. (2017a). Customer dissatisfaction and satisfaction with augmented reality in shopping and entertainment. Journal of Consumer Satisfaction, Dissatisfaction and Complaining Behavior, 30, 1-22.

Poushneh, A., \& Vasquez-Parraga, A. Z. (2017b). Discernible impact of augmented reality on retail customer's experience, satisfaction and willingness to buy. Journal of Retailing and Consumer Services, 34, 229-234.

Poushneh, A. (2018). Augmented reality in retail: A trade-off between user's control of access to personal information and augmentation quality. Journal of Retailing and Consumer Services, 41, 169-176. 
Rauschnabel, P. A., Brem, A., \& Ivens, B. S. (2015). Who will buy smart glasses? Empirical results of two pre-market-entry studies on the role of personality in individual awareness and intended adoption of Google Glass wearables. Computers in Human Behavior, 49, 635-647.

Rauschnabel, P. A., Rossmann, A., \& tom Dieck. M. C. (2017). An Adoption Framework for Mobile Augmented Reality Games: The Case of Pokémon Go. Computers in Human Behavior, 76(6), 276-286.

Reimann, M., \& Aron, A. (2009). Self-expansion motivation and inclusion of brands in self. Handbook of brand relationships, 65-81.

Rese, A., Schreiber, S., \& Baier, D. (2014). Technology acceptance modelling of augmented reality at the point of sale: Can surveys be replaced by an analysis of online reviews? Journal of Retailing and Consumer Services, 21(5), 869-876.

Rese, A., Baier, D., Geyer-Schulz, A., \& Schreiber, S. (2017). How augmented reality apps are accepted by consumers: A comparative analysis using scales and opinions. Technological Forecasting and Social Change, 124, 306-319. 
Scholz, J. \& Smith, A.N. (2016). Augmented reality: Designing immersive experiences that maximize consumer engagement. Business Horizons, 59(2), pp.149-161.

Shankar V., Balasubramanian S. (2009). Mobile marketing: A synthesis and prognosis. Journal of Interactive Marketing, 23(2):118-129.

Shankar V., Kleijnen M., Ramanathan S., Rizley R., Holland S., Morrissey S. (2016). Mobile shopper marketing: Key issues, current insights, and future research avenues. Journal of Interactive Marketing, 34:37-48.

Shankar, V., Venkatesh, A., Hofacker, C., \& Naik, P. (2010). Mobile marketing in the retailing environment: current insights and future research avenues. Journal of Interactive Marketing, 24(2), 111-120.

Shove, E. (2007). The design of everyday life. Berg.

Spaid, B. I., \& Flint, D. J. (2014). The meaning of shopping experiences augmented by mobile internet devices. Journal of Marketing Theory and Practice, 22(1), 73-90.

Suler, J. (2004). The online disinhibition effect. Cyberpsychology \& Behavior, 7(3), 321326. 
Thompson, C. J. (1997). Interpreting Consumers: A Hermeneutical Framework for Deriving Marketing Insights from the Texts of Consumers' Consumption Stories. Journal of Marketing Research, 34(4), 438-455.

tom Dieck, M. C., Jung, T., \& Rauschnabel, P. A. (2018). Determining Visitor Engagement Through Augmented Reality at Science Festivals: An Experience Economy Perspective. Computers in Human Behavior 82, 44-53.

Verhoef, P., Stephen A., Kannan P.K., Luo, X., Abhishek V., Andrews M., Bart, Y., Datta H., Fong N., Hoffman, D., Hu, MM., Novak, T., Rand, W., Zhang, Y. (2017). Consumer Connectivity in a Complex, Technology-enabled, and Mobile-oriented World with Smart Products, Journal of Interactive Marketing 40, 1-8.

Walsh, S. P., White, K. M., \& McD Young, R. (2010). Needing to connect: The effect of self and others on young people's involvement with their mobile phones. Australian Journal of Psychology, 62(4), 194-203.

Yaoyuneyong, G., Foster, J., Johnson, E., \& Johnson, D. (2016). Augmented reality marketing: Consumer preferences and attitudes toward hypermedia print ads. Journal of Interactive Advertising, 16(1), 16-30. 
Yim, M. Y. C., Chu, S. C., \& Sauer, P. L. (2017). Is Augmented Reality Technology an Effective Tool for E-commerce? An Interactivity and Vividness Perspective. Journal of Interactive Marketing, 39, 89-103. 